\title{
Algoritmos Genéticos aplicado ao mundo de Wumpus: uma comparação entre agentes baseados em regras e agentes inteligentes
}

\author{
Victor S. Martins ${ }^{1}$, Julio Cezar Gonçalves de Freitas $^{1}$, Ingrid Nery Mendes ${ }^{1}$, \\ Otávio Noura Teixeira ${ }^{1}$ \\ ${ }^{1}$ Universidade Federal do Pará (UFPA) \\ Programa de Pós-graduação em Computação Aplicada (PPCA) \\ Campus Universitário de Tucuruí - Pará - Brazil \\ victorsmeufpa.br, \{julio.freitas, ingrid.mendes\}@tucurui.ufpa.br \\ onouraegmail.com
}

\begin{abstract}
The present work compares the application of intelligent agents applied to the Wumpus World. The agents studied are based on rules and genteic algorithms (GA). The experiments show the possibility of using both techniques for search problems, as well as a better result for that agent based on AG. Furthermore, it compares variations of GAs, investigating the use of elitism in the next generation selection process.
\end{abstract}

Resumo. O presente trabalho compara a aplicação de agentes inteligentes aplicados ao mundo do Wumpus. Os agentes estudados são baseados em regras e algoritmos genéticos $(A G)$. Os experimentos mostram a possibilidade de utilização de ambas técnicas para problemas de busca, bem como um melhor resultado para aquele agente baseado em AG. Além disso, compara variações dos AGs, investigando a utilização de elitismo no processo de seleção da próxima geração.

\section{Introdução}

O mundo de Wumpus é um exemplo de aplicação para agente baseado em conhecimento que representa o raciocínio e o planejamento. É composto por uma caverna com 16 salas (modelo matriz $4 \times 4$ ), onde todas as salas são conectadas umas às outras. A caverna é composta por 03 itens: a) poços, que em suas proximidades geram uma brisa; b) o monstro Wumpus, que dá nome ao ambiente e expele fedor nas casas ao seu redor; e, c) o ouro, que apresenta brilho nas salas do seu entorno. [Russell and Norvig 2010] Este ouro é o objetivo final do jogo, que ao ser coletado pelo agente do experimento (caçador), é recompensado com +1000 pontos, não devendo ter caído em nenhum dos poços, ou morto pelo Wumpus antes de retornar ao seu ponto de partida (posição 1x1 da matriz).

Para que o agente aprenda a realizar a tarefa que lhe foi proposta, existem outras recompensas (-) ou punições (+) que podem ser aplicadas, tais como: para cada movimento $(-1)$, disparo da flecha $(-10)$, e matar o Wumpus $(+50)$. 


\subsection{Algoritmos Genéticos (AG)}

São algoritmos de busca baseados na mecânica da seleção e genética natural, combinando a sobrevivência entre os mais aptos com trocas de informações estruturadas [Goldberg 1989]. É uma meta-heurística pertencente a uma larga classe de algoritmos evolucionários na informática e matemática computacional. São frequentemente utilizados para a criação de soluções de alta qualidade em problemas de busca e otimização, focando em operadores bioinspirados como: reprodução, cruzamento e mutação [Whitley 1994],[Alam et al. 2020] e [Sivaraj and Ravichandran 2011].

De forma resumida, o AG inicia com uma população aleatória onde cada indivíduo representa uma solução do problema de busca, eles são avaliados e selecionados, para que seja aplicado sobre esses indivíduos os operadores bioinspirados, resultando na próxima geração. O processo é iterativo e tem condições de parada tais como: número máximo de gerações e valor mínimo ou máximo de solução do melhor indivíduo.

Esse processo assegura que a nova geração seja totalmente nova, porém, possuindo característica de seus antecedentes para manter sua capacidade de adaptação adquirida nas gerações anteriores, por meio do cruzamento [Alam et al. 2020], além da inserção de características aleatórias por meio da mutação, com a finalidade de manter a heterogeneidade [Sivaraj and Ravichandran 2011].

\subsection{Agentes Inteligentes (AI)}

Um agente inteligente é uma entidade autônoma capaz de executar suas atividades direcionando-se para o alcance dos objetivos em um ambiente utilizando-se de sensores e atuadores [Anderson and Anderson 2020]. Os agentes inteligentes são capazes de aprender ou utilizar conhecimentos adquiridos para atingir seus objetivos que podem ser simples ou extremamente complexos [Russell and Norvig 2010]. Segundo [Padgham and Winikoff 2004], um agente inteligente é capaz de responder de maneira oportuna sobre as mudanças no ambiente e são capazes de executar ações para a realização de seu objetivo de forma robusta e flexível [Cointe et al. 2020].

\section{Materiais e métodos}

\subsection{Configuração dos Mundos}

Mundos com 3 tamanhos diferentes foram utilizados para a realização dos testes: $4 \times 4$, $6 \times 6$ e 8x8, sendo que para cada um deles foram gerados 5 mundos com configurações aleatórias. Especificamente para o AG, em virtude do seu caráter aleatório, realizou-se 10 testes em cada um desses mundos.

\subsection{Movimentos Possíveis}

São 6 (seis) movimentos possíveis do agente dentro do mundo, designados por um número inteiro que representa o gene dentro do cromossomo de um indivíduo do AG ou o próximo movimento do AI.

Os movimentos são: a) GOFORWARD (0): segue para próxima casa; b) TURNLEFT (1): vire $90^{\circ}$ para esquerda; c) TURNRIGHT: (2) vire $90^{\circ}$ para direita; d) GRAB (3), ação para coletar o ouro; e) SHOOT (4): atirar flecha; f) CLIMB (5): escala para saída do Mundo, quando na casa inicial $(1,1)$; f) NÃO-MOVIMENTO (6): utilizado para criar um efeito de cromossomo variável, utilizado exclusivamente no AG, pois o agente não executa nenhum movimento. 


\subsection{Configuração do Algoritmo Genético}

A configuração fixa que foi utilizada nos testes conteve os seguintes parâmetros: Taxa de Crossover com valor 0,5 (P1); Taxa de Mutação com valor 0,15 (P2); Indivíduos no torneio com valor 3 (P3); Tamanho da População com valor 100 (P4); Tamanho do indivíduo com valor 200 (P5); Elitismo com valor 0,02 (P6); e Gerações com valor 100 (P7).

Importante registrar, que foram realizados testes de AGs com e sem elitismo [9], que basicamente implica que uma porcentagem da população com os melhores fitness são clonados para a próxima geração. As configurações de cada teste foram as seguintes: Teste 01 com elitismo e gene 6 (e6); Teste 02 com elitismo e sem gene 6 (ex); Teste 03 sem elitismo e com gene 6 (x6); e o Teste 04 sem elitismo e sem gene 6 (xx).

\subsection{Cálculo do Fitness}

Para o cálculo do fitness de cada indivíduo, métrica que se pretende maximizar com o Algoritmo Genético, foi utilizado o somatório da pontuação do jogo, conforme indicada na Introdução, dividido pelo número de movimentos executados.

\section{Resultados}

Para análise dos resultados, foram definidos 3 objetivos principais e calculados os percentuais de vezes que o Agente Baseado em lógica (reativo), e o Agente baseado em AG, conseguiu atingir cada um deles. Os objetivos são: Pegar o Ouro e sair da caverna (Ob1), Matar o Wumpus (Ob2), e apenas pegar o ouro (Ob3).

Nas Figuras 1.a e 1.b verifica-se, para ambos agentes, que a dificuldade de realizar a os objetivos $\mathrm{Ob} 1$ e $\mathrm{Ob} 3$ aumenta conforme o aumento do tamanho do mundo, sendo que para o agente reativo, na configuração $8 x 8$, esses objetivos não foram atingidos, sugerindo que com o aumento dos mundos eles são mais difíceis em comparação ao Ob2 Figura 1.c.

Verifica-se ainda, que o objetivo de matar o Wumpus se tornou mais fácil para o agente baseado em AG quando aumentou-se o tamanho dos mundos, com uma leve diminuição nesse índice da configuração $6 \times 6$ para a 8x8, mas esta última ainda maior que a $4 \times 4$.

Em relação às estratégias de elitismo e "gene 6", verifica-se que a utilização dos dois em conjunto foi interessante para a configuração de mundo 6x6, especificamente para o objetivo de pegar o ouro e sair da caverna (Figura 1.a), mas que não teve influência para o objetivo de matar o Wumpus de um modo geral, pois a estratégia sem elitismo e sem "gene 6" (xx) conseguiu os melhores resultados, exceto para o 4x4 onde a estratégia apenas com o "gene 6" (x6) obteve melhores índices.

Verifica-se ainda, que o objetivo de matar o Wumpus se tornou mais fácil para o agente baseado em AG quando aumentou-se o tamanho dos mundos, com uma leve diminuição nesse índice da configuração $6 \times 6$ para a 8x8, mas esta última ainda maior que a $4 \times 4$.

Em relação às estratégias de elitismo e "gene 6", verifica-se que a utilização dos dois em conjunto foi interessante para a configuração de mundo 6x6, especificamente para o objetivo de pegar o ouro e sair da caverna (Figura 1.a), mas que não teve influência 

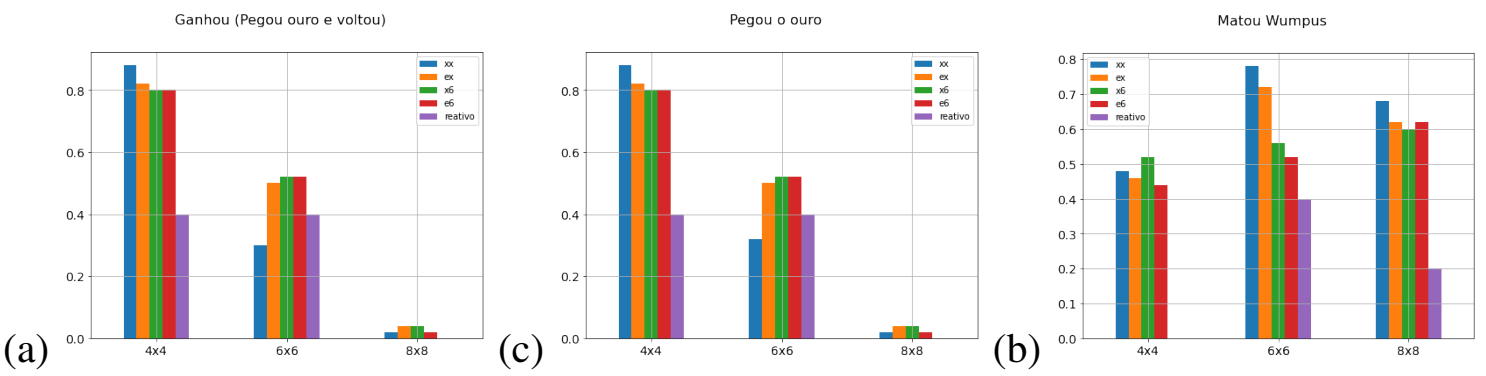

Figure 1. (a) Proporção de vezes que os Agentes conseguiram coletar o ouro e sair da caverna. (b) Proporção de vezes que os Agentes conseguiram coletar o ouro. (c) Proporção de vezes que os Agentes conseguiram matar o Wumpus.

para o objetivo de matar o Wumpus de um modo geral, pois a estratégia sem elitismo e sem "gene 6" (xx) conseguiu os melhores resultados, exceto para o $4 \times 4$ onde a estratégia apenas com o "gene 6" (x6) obteve melhores índices.

\section{Conclusão}

Por meio dos resultados é possível perceber a maior dificuldade dos agentes em atingir os objetivos $\mathrm{Ob} 1$ e $\mathrm{Ob} 3$ proporcionalmente ao tamanho dos mundos, não ocorrendo do mesmo modo para o objetivo de matar o Wumpus. Nesse último caso, a forma de cálculo do fitness para o AG pode ter influenciado, uma vez que apenas pegar o ouro não gera nenhuma pontuação e matar o Wumpus aumenta em 50 pontos, assim, os indivíduos, em mundos maiores, como não conseguiam sair da caverna, adaptaram-se para a tarefa mais fácil e que gerava um melhor valor de fitness, no caso, matar o Wumpus. Percebeuse também que as estratégias de elitismo e "gene 6" tiveram influência apenas para o objetivo de ganhar o jogo, e exclusivamente para o mundo 6x6.

\section{References}

Alam, T., Qamar, S., Dixit, A., and Benaida, M. (2020). Genetic algorithm: Reviews, implementations, and applications. CoRR, abs/2007.12673.

Anderson, M. and Anderson, S. (2020). Machine Ethics: Creating an Ethical Intelligent Agent, pages 237-248.

Cointe, N., Bonnet, G., and Boissier, O. (2020). Ethics-based cooperation in multi-agent systems. In Verhagen, H., Borit, M., Bravo, G., and Wijermans, N., editors, Advances in Social Simulation, pages 101-116, Cham. Springer International Publishing.

Goldberg, D. E. (1989). Genetic Algorithms in Search, Optimization, and Machine Learning. Addison-Wesley, New York.

Padgham, L. and Winikoff, M. (2004). Developing Intelligent Agent Systems. John Wiley \& Sons, Ltd.

Russell, S. and Norvig, P. (2010). Artificial Intelligence: A Modern Approach. Prentice Hall, 3 edition.

Sivaraj, R. and Ravichandran, T. (2011). A review of selection methods in genetic algorithm. International Journal of Engineering Science and Technology, 3.

Whitley, D. (1994). A genetic algorithm tutorial. Statistics and Computing, 4(2):65-85. 